\title{
A relação de parceria entre o INCRA e os movimentos sociais no processo de implementação das políticas de reforma agrária
}

Camila Penna*

\section{Resumo}

Movimentos sociais são geralmente considerados agentes de mudança social. Suas ações podem levar a mudanças em regimes políticos ou na cultura política de um país. Mas como avaliar o impacto real dos movimentos nas políticas públicas? Neste artigo argumento que, para apreender como as ações dos movimentos sociais afetam políticas, é necessário olhar para o Estado, onde as políticas são formuladas e implementadas. Discuto como os movimentos sociais brasileiros de luta pela reforma agrária influenciam a autarquia estatal responsável pela reforma agrária, o Instituto Nacional de Colonização e Reforma Agrária (INCRA). Por meio de uma descrição etnográfica das interações cotidianas entre burocratas e lideranças de movimentos que ocorrem dentro de uma Superintendência Regional do INCRA, demonstro como os movimentos sociais influenciam as políticas da instituição. Agindo concomitantemente na arena político-institucional e no campo das ações coletivas de protesto, eles definem aspectos-chave das políticas de reforma agrária, como a seleção de propriedades a serem desapropriadas e a seleção de famílias a serem assentadas pela autarquia..

\section{Palavras-chave}

INCRA. Movimentos sociais. Parceria.

\begin{abstract}
Social movements are usually seen as agents of social change. Their actions can lead to changes in political regimes and in national political cultures. But how to assess the actual impact of social movements in public policies? This paper argues that in order to grasp how movements' actions affect policies it's necessary to take a closer look at the state, where policies are actually formulated and implemented. I discuss the case of Brazilian rural
\end{abstract}

\footnotetext{
* Doutora em Sociologia pela Universidade de Brasília; bolsista do Programa Nacional de PósDoutorado da Coordenação de Aperfeiçoamento de Pessoal de Nível Superior (CAPES) no âmbito do Instituto de Ciência Política (IPOL), da Universidade de Brasília (UnB). E-mail: camilapennac@gmail.com .
} 
movements' influence on the state institution responsible for agrarian reform. Through an ethnographical description of the interactions between bureaucrats and movement activists inside a regional state office I demonstrate how social movements influence this institution's policies. By concomitantly acting on the political-institutional arena and on the protest arena they define key aspects of the agrarian reform policies, such as the selection of properties to be expropriated and the selection of policy clients.

\section{Keywords}

INCRA. Social movements. Partnership.

\section{Introdução}

$\mathrm{O}$ artigo analisa como os movimentos sociais afetam políticas do Estado. Descreve o caso da influência dos movimentos rurais de luta pela reforma agrária no Instituto de Colonização e Reforma Agrária (INCRA), autarquia responsável pela execução das políticas de reforma agrária. O argumento central é o de que, para apreender o impacto dos movimentos nas políticas públicas, é essencial olhar para o Estado, local onde essas políticas são de fato feitas. Também argumento que a observação etnográfica é o método mais adequado para compreender como os movimentos influenciam as práticas cotidianas dos burocratas do Estado, e, por conseguinte, a forma como as políticas são implementadas.

As relações entre os movimentos sociais rurais e o INCRA foram observadas por meio de trabalho etnográfico, que durou nove meses e foi realizado na Superintendência Regional de Marabá (SR-27), uma das 30 Superintendências da autarquia. Durante esse período, testemunhei uma interação próxima e frequente entre servidores da SR e lideranças de movimentos. Políticas de reforma agrária são fortemente influenciadas por movimentos sociais, que têm um profundo conhecimento dos procedimentos burocráticos internos e exercem influência nos órgãos regionais, tanto por meio de pressão com ações coletivas de protesto como através da participação em reuniões rotineiras e em negociações com servidores da autarquia.

Primeiramente o artigo apresenta algumas contribuições teóricas ao estudo das relações entre Estado e movimentos sociais. A seção seguinte discute o caso da literatura sobre movimentos rurais no Brasil e sua interação 
com o Estado ao longo do tempo. Por fim, o artigo traz a descrição etnográfica do caso sob análise e apresenta as principais conclusões permitidas pela interpretação dos dados obtidos no campo.

\section{Relações entre Estado e movimentos sociais}

As relações entre movimentos e Estado foram abordadas em seus diversos aspectos pelas teorias de movimentos sociais. Tilly (1995) e Jonhston (2011) argumentam que movimentos sociais foram importantes para a constituição do Estado democrático, uma vez que mobilizações realizadas ao longo do tempo contribuíram para uma abertura à participação política de classes populares tradicionalmente excluídas. O que começou como medidas tomadas pelas elites para evitar revoltas e revoluções gradualmente se desdobrou em práticas democráticas institucionalizadas.

Para analisar o complexo universo de relações entre Estados e movimentos sociais, Jenkins e Klandermans (1995) propuseram um modelo em forma de losango com quatro vértices: Estado, movimentos sociais, cidadãos e sistema de representação política. Nesse modelo, todos os quatro grupos de atores, representados pelos vértices, estão conectados, e as ações de cada um tem impacto sobre os outros.

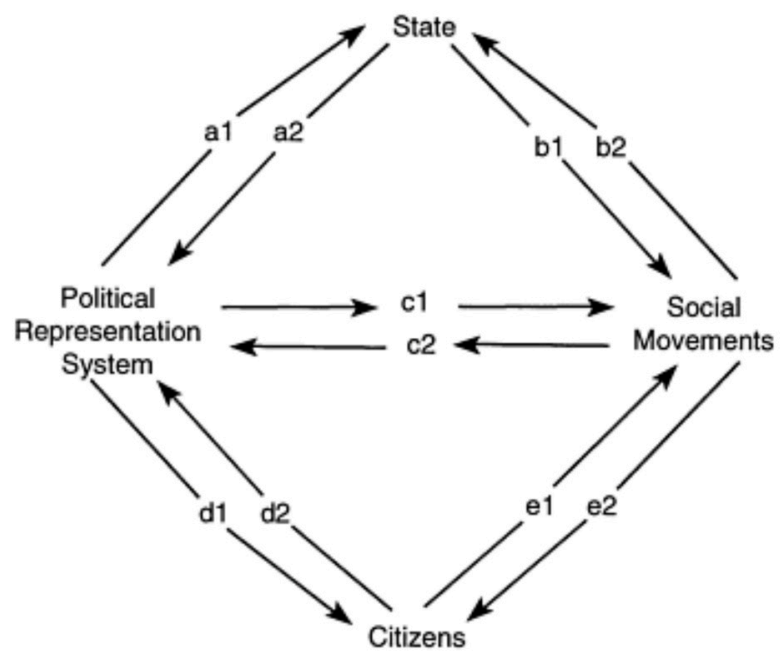

Figura 1: Modelo em forma de losango

Fonte: JENKINS; KLANDERMANS, 1995: 4. 
Cidadãos estão conectados ao Estado pelo sistema político de representação, que abarca os partidos políticos, e pelos movimentos sociais, que se engajam em ações de protesto como tentativas de influenciar políticas públicas. O ponto que os autores fazem é o de que é necessário olhar "para o impacto do protesto social e dos esforços dos movimentos sociais no sistema político, e também para o impacto do sistema político de volta nos movimentos sociais“ (JENKINS; KLANDERMANS, 1995: 4-5).

A literatura sobre oportunidades políticas contribui para a análise de como sistemas políticos influenciam ações coletivas, ao gerar expectativas positivas e negativas sobre a probabilidade de sucesso (TARROW, 1998). Algumas das dimensões do ambiente político estão relacionadas a aspectos do Estado: abertura à participação política, grau de tolerância em relação às ações de protesto (ZALD, 1996); definição do que é uma forma legal de protesto e policiamento das ações de protesto (DELLA PORTA, 2006); alinhamento político entre partidos e existência de partidos na aliança governamental que apoiam movimentos sociais (TILLY, 2006).

A noção de repertório também é importante para compreender como movimentos constroem estratégias de luta ao longo do tempo. Repertórios são conjuntos de performances pelas quais movimentos sociais levam a cabo ações de protesto (TILLY, 2006). Performances como marchas, ocupações, atos, abaixo-assinados, entre outras, constituem repertórios de protesto. As formas de ação coletiva escolhidas pelos movimentos sociais para apresentar suas reivindicações são definidas pela interação com o Estado ao longo do tempo (AUYERO, 2002; TILLY, 2006). De acordo com as respostas do Estado às performances de protesto utilizadas pelos movimentos sociais, eles definem quais repertórios são mais eficientes para conseguir seus pleitos.

Para compreender de forma mais ampla os aspectos envolvidos na relação entre movimentos e Estado, também é importante olhar para os impactos dos movimentos nos sistemas políticos. Não apenas os movimentos agem realizando ações coletivas de protesto, eles também agem por meio da política institucional. Goldstone (2003) argumenta que é importante estudar a participação dos movimentos na política convencional. Essa forma de participação é complementar ao protesto, e os movimentos usam ambas as estratégias para obter seus objetivos e influenciar políticas. Munck (1995) também chama atenção para diferentes arenas, nas quais os movimentos agem: a arena social, caracterizada pelas ações coletivas, e a arena políticoinstitucional. De acordo com o autor, a ação na arena político-institucional poderia, em casos de movimentos com orientação política fraca, comprometer a autonomia em relação ao Estado. 
Ações de movimentos, tanto na esfera da política convencional como na esfera do protesto, conecta-os também com os partidos políticos. Burstein (1999) argumenta que movimentos sociais são parte da política democrática e, para avaliar os resultados de suas ações, é importante olhar para seu papel no sistema representativo. Movimentos podem influenciar políticas públicas através do processo eleitoral. Suas ações de protesto e suas atividades na política convencional podem fazer com que determinados temas adquiram caráter prioritário na agenda política.

Os impactos dos movimentos no sistema político também podem ser observados na organização e nas práticas de instituições estatais. Meyer (2003) argumenta que as ações dos movimentos podem resultar em mudanças na organização interna do Estado. Ele aponta que a criação de novos departamentos e agências por governos em resposta a demandas e pressões de movimentos não é incomum. Além de influenciar a organização do Estado, os movimentos podem mudar práticas internas de agências estatais e interferir na forma como os burocratas executam seu trabalho, afetando, assim, as políticas públicas de uma maneira menos óbvia, mas altamente eficaz. Esse foi o caso verificado OK na observação etnográfica realizada na Superintendência do INCRA.

Para avaliar os impactos dos movimentos sociais nas políticas públicas, é crucial olhar para o local onde essas políticas são formuladas e implementadas: as agências estatais que executam políticas em contato com os beneficiários. Essas agências são compostas por uma burocracia que trabalha na linha de frente da implementação de políticas, conhecida como street-level bureaucracy (LIPSKY, 1980). Os servidores públicos têm opiniões, posições políticas, ideologias e afiliações que influenciam como eles interagem com clientes e definem o formato final da política pública (DUBOIS, 2010). Na Superintendência Regional estudada, os servidores públicos interagem diariamente com lideranças de movimentos que representam os clientes da reforma agrária atendidos pelas políticas do INCRA.

Estudar a interação que toma lugar entre movimentos sociais e burocratas dentro da agência estatal é tão importante para explicar os resultados das ações dos movimentos como analisar as oportunidades políticas à sua volta. Ademais, para entender os vários aspectos envolvidos na relação entre movimentos e Estado, a observação etnográfica é o método mais adequado. Observar o trabalho cotidiano dos burocratas e suas relações com os clientes a partir de um olhar etnográfico ajuda a compreender como as políticas públicas são executadas no dia a dia da agência estatal (SHARMA; GUPTA, 2006; HERZFELD, 2005). 


\section{Relações entre Estado e movimentos sociais no caso estudado}

Mais do que em qualquer outra esfera política, o processo de reforma agrária no Brasil tem sido caracterizado por um papel protagonista dos movimentos sociais. Alguns dos mais organizados movimentos do país são as organizações sociais rurais, que têm lutado pela reforma agrária nas últimas três décadas. Dentre elas, a mais estudada e conhecida é o MST (Movimento Rural dos Trabalhadores Sem-Terra).

Além da literatura que foca em aspectos internos desses movimentos, existem algumas contribuições que abordam sua relação com o Estado. A criação e o desenvolvimento do MST, por exemplo, já foram analisados olhando-se para mudanças nas oportunidades políticas ao longo do tempo. As políticas de reforma agrária e as atividades de movimentos sociais de luta pela terra que começaram nos anos 1950 e se intensificaram nos anos de 1960 foram interrompidas pelo golpe militar de 1964, que instaurou um regime autoritário que durou aproximadamente 20 anos. Durante esse período, houve pouco espaço para políticas de reforma agrária e nenhum espaço para o protesto dos movimentos sociais.

Com a transição para a democracia em 1980, a repressão diminuiu, e as oportunidades políticas foram mais favoráveis às atividades dos movimentos sociais. Nesse contexto, o MST e outros movimentos sociais rurais começaram a organizar ações coletivas massivas de protesto. Alguns autores argumentam que essa abertura do regime político em meados dos anos 1980 influenciou positivamente o desenvolvimento dos movimentos sociais rurais, uma vez que o regime político se tornou mais aberto e menos repressivo (ONDETTI, 2008; NAVARRO, 2010). Cabe ressaltar que a organização e a atuação dos movimentos no contexto de transição foram fundamentais para a abertura de oportunidades políticas.

Mais adiante, em meados dos anos 1990, outra mudança na estrutura de oportunidades políticas teria influenciado o crescimento exponencial dos movimentos sociais. Em abril de 1996, depois de uma violenta repressão de uma manifestação do MST em uma rodovia no município de Eldorado dos Carajás, no Sudeste do Pará, a polícia militar estadual executou 19 militantes do movimento. O evento, que ficou conhecido como Massacre de Eldorado dos Carajás, teve repercussão internacional, e isso trouxe o tema da reforma agrária para o topo da agenda política. Em resposta à pressão do movimento, o governo FHC passou a dar mais atenção para as políticas de reforma agrária e começou um programa massivo de desapropriação de terras e criação de 
assentamentos (ONDETTI, 2006; FERNANDES, 2000). A ampliação das políticas de reforma agrária nesse contexto de alta visibilidade do tema e de intensificação das atividades dos movimentos também levou ao crescimento e à ampliação das bases desses movimentos. Nesse contexto de intensa atuação e organização dos movimentos, a ocupação de terras se estabeleceu como repertório por excelência para se reivindicar reforma agrária no Brasil, uma vez que ocupar terras aparecia no horizonte das pessoas como uma possibilidade real de acesso à terra (MEDEIROS, 2000).

Esse repertório é caracterizado pela ocupação coletiva de uma propriedade pleiteada pelo movimento e pelo estabelecimento de um acampamento organizado na área da propriedade ou às suas margens. Ao se tornar o repertório mais comum, utilizado por todas as organizações rurais que reivindicam desapropriação de terras e criação de assentamentos (ROSA, 2011), a ocupação seguida pelo acampamento se tornou a linguagem por meio da qual os movimentos comunicam suas demandas ao Estado (SIGAUD, 2005). O repertório foi adquirindo reconhecimento do Estado na medida em que o INCRA foi, ao longo do tempo, negociando as demandas dos acampados com as lideranças dos movimentos. Ao fazê-lo, a autarquia reconhecia não apenas a ocupação e o acampamento como formas de reivindicação legítimas, mas também os movimentos como representantes dos beneficiários das políticas de reforma agrária (ROSA, 2011). A seguir, explicarei por que esse é um exemplo de como os movimentos podem influenciar práticas do Estado.

Intini (2004) e Assis (2007) chamam atenção para o impacto dos movimentos rurais na organização estatal. Os autores realizaram pesquisa na região sul e sudeste do Pará, local onde ocorreu o Massacre de Eldorado dos Carajás, e argumentaram que a pressão exercida após o massacre pelos movimentos organizados influenciou a decisão do governo de criar uma nova Superintendência Regional do INCRA na região, o que ocorreu em $1996^{1}$, quando foi criada a SR(27), em Marabá. Após a criação da SR, o

\footnotetext{
${ }^{1}$ O Massacre e a criação da SR (27) coincidem com um momento de crescimento do MST na região. O movimento já atuava no sul e no sudeste do Pará desde o final da década de 1980, mas após o evento em Eldorado dos Carajás ganhou maior visibilidade, o que passou a influenciar os repertórios de ação do movimento sindical, organização mais antiga e de maior base na região. Atualmente o movimento sindical, agora dividido entre FETAGRI e FETARF, continua tendo a maior base entre assentados de reforma agrária. Contudo, desde os anos 1990, utiliza o mesmo repertório de ocupação de terra do MST (PENNA, 2013).
} 
poder de barganha dos movimentos na região aumentou significativamente, e eles passaram a organizar acampamentos periódicos e massivos na sede da nova Superintendência. Com seus grandes acampamentos, no final dos anos 1990, os movimentos da região conseguiram influenciar a escolha do Superintendente Regional do novo órgão, após exigir que o gestor anterior fosse exonerado como condição para a desocupação da sede da autarquia (INTINI, 2004). Essa Superintendência em Marabá, a SR(27), foi o local escolhido para a observação etnográfica devido à sua forte e histórica conexão com os movimentos sociais de luta pela reforma agrária.

Em 2003, outra mudança no contexto político brasileiro afetou os movimentos sociais. O Partido dos Trabalhadores (PT) ganhou pela primeira vez as eleições para presidência. Isso representou uma mudança significativa no campo de ação política dos movimentos, uma vez que o partido tinha conexões históricas com os movimentos rurais. Desde a sua criação, em 1980, o PT apoiou a luta pela reforma agrária dos movimentos rurais. Igualmente, as lideranças dos movimentos geralmente apoiam o partido e conseguem votos para seus candidatos.

Vergara-Camus (2009) argumenta que a relação entre o MST e o PT sempre foi estratégica para a ação política do movimento. Ao longo de sua história, o MST apoiou candidatos do partido, e alguns de seus militantes se candidataram a cargos eletivos pelo PT. Existem, atualmente, políticos eleitos que foram militantes ou apoiadores do movimento que frequentemente defendem a causa da reforma agrária. No nível federal, os políticos eleitos para cargos do legislativo compõem o "Núcleo Agrário", ou a bancada da reforma agrária.

A literatura revisada até aqui ajuda a compreender como os movimentos sociais de luta pela reforma agrária têm interagido com o Estado no Brasil ao longo do tempo. Não obstante, ela se detém nos movimentos e olha para a interação a partir do ponto de vista dos movimentos, enquanto tenta avaliar seus impactos no sistema político. Para apreender como os movimentos afetam as políticas públicas, é fundamental olhar para o lugar onde essas políticas são feitas. É por isso que este artigo tem como foco de observação a autarquia responsável pela implementação de políticas de reforma agrária. Olha-se aqui para a interação entre Estado e movimentos de dentro de uma Superintendência do INCRA e a partir do ponto de vista de seus burocratas, que estão cotidianamente em contato com militantes dos movimentos.

O INCRA é a autarquia criada em 1970 com o propósito de executar políticas de colonização e de reforma agrária. Ela é atualmente vinculada 
ao Ministério do Desenvolvimento Agrário (MDA) e está descentralizada em 30 Superintendências regionais localizadas em cada estado, além da sede em Brasília ${ }^{2}$. Regiões com alto número de conflitos agrários, como o Pará, têm mais de uma Superintendência. No estado do Pará existem três Superintendências Regionais do INCRA: Belém (SR-01), Marabá (SR-27) e Santarém (SR-30) ${ }^{3}$.

As Superintendências do INCRA executam políticas de reforma agrária no nível regional através de contato regular com movimentos sociais. Elas são locais de interações rotineiras entre burocratas e militantes de movimentos. A grande maioria dos servidores púbicos que trabalha nessas regionais ingressou no INCRA por meio de concurso público federal. Há, contudo, gestores, como o caso de alguns superintendentes, que não são servidores de carreira e que ocupam cargos de comissão e foram nomeados devido às suas conexões políticas com o partido. Atualmente, mais da metade das SR são geridas por superintendentes indicados por grupos políticos regionais ligados ao PT.

A observação etnográfica foi conduzida na Superintendência de Marabá (SR-27), que cuida da região do sul e do sudeste do Pará. Essa é uma das mais violentas regiões do país em termos de conflitos agrários, de acordo com os dados sobre Conflito no Campo, produzidos anualmente pela Comissão Pastoral da Terra (CPT). A própria Superintendência Regional em Marabá foi criada no contexto do Massacre de Eldorado dos Carajás e após pressão dos movimentos sociais.

A pesquisa de campo foi realizada entre outubro de 2011 e junho de 2012, período no qual fiquei na Superintendência do INCRA de Marabá. Como parte do trabalho de campo, realizei entrevistas com os servidores para saber suas impressões sobre as ações dos movimentos sociais; participei de reuniões entre gestores e servidores da SR(27) e lideranças de movimentos;

\footnotetext{
${ }^{2}$ A força de trabalho do INCRA é de aproximadamente 6 mil servidores, o que faz do Instituto uma das maiores autarquias brasileiras, menor apenas que o INSS (Instituto Nacional de Seguridade Social), que tem 37 mil servidores. Dentre os servidores do INCRA, 2 mil ingressaram após 2004, e 2 mil podem se aposentar até o final de 2014 - o que indica uma força de trabalho dividida ao meio em termos do tempo de serviço.

3 De acordo com dados oficiais disponíveis no site INCRA, atualmente o número total de famílias assentadas é de 956.453. Destas, 227.495 estão assentadas no estado do Pará, divididas entre as três Superintendências da seguinte forma: SR-01 com 84.688, SR-30 com 73.150, e SR-27 com 69.657 (http://www.incra.gov.br/reforma_agraria).
} 
e acompanhei servidores em seu trabalho de atendimento aos clientes que vão à Superintendência.

A seguir, apresento alguns dados etnográficos que revelam como é a interação entre burocratas do Estado e militantes de movimentos que ocorre no interior da Superintendência de Marabá. A relação entre o INCRA e os movimentos sociais é frequentemente denominada "parceria", tanto pelos servidores como pelos militantes. A descrição a seguir elucida o que essa "relação de parceria" significa.

\section{Relação de Parceria}

Cheguei à Superintendência de Marabá em 9 de outubro de 2011. A parte interna do prédio que sedia a SR é formada por um complexo de várias casas interligadas, cercadas por uma grande área verde com árvores e grama. A sala de espera está sempre lotada de trabalhadores rurais que esperam por atendimento. Uma das atendentes da recepção me conta que aproximadamente cem pessoas vêm à SR diariamente. A maioria são clientes $^{4}$ que vêm pedir documentos oficiais e buscar informações sobre seu assentamento. Todos trazem um ofício assinado pelo sindicato ou pela organização do movimento, que certifica a autenticidade do pleito apresentado ao INCRA. Esses ofícios são entregues às atendentes, que depois os colocam em um arquivo organizado por ordem cronológica.

\footnotetext{
${ }^{4}$ Palavra que os servidores, notadamente os mais antigos, utilizam para se referir aos beneficiários do Programa Nacional de Reforma Agrária.
} 


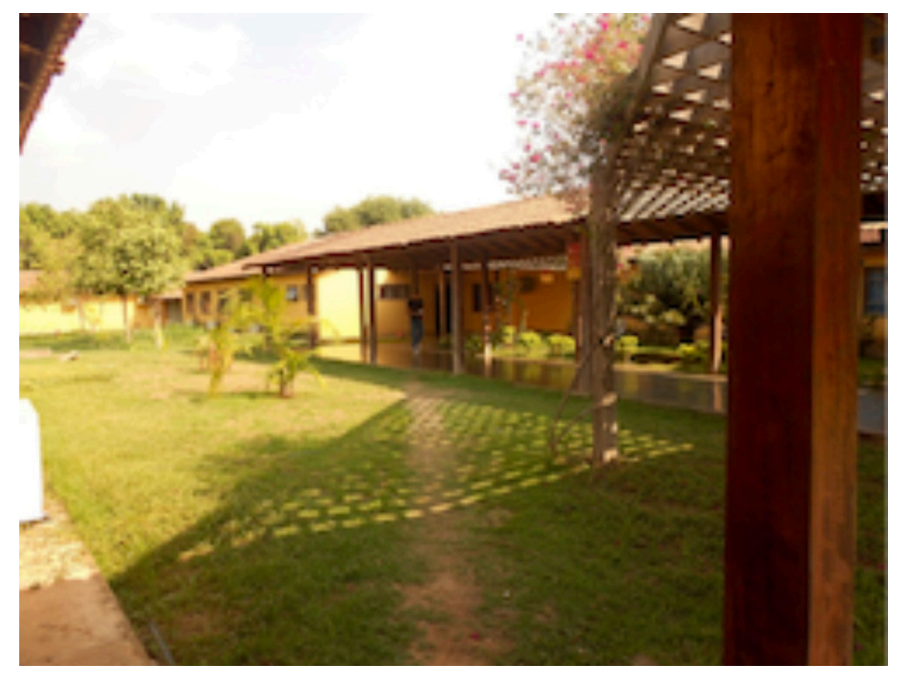

Figura 2: Interior da SR (27)

Lideranças de movimentos também passam pela recepção da SR diariamente. Elas já são conhecidas de todos os servidores, vêm ao INCRA semanalmente e tratam as atendentes pelo nome. Ao contrário dos clientes usuais, não esperam para ser atendidos, apenas comunicam às atendentes para onde estão indo e entram na SR. Normalmente, eles informam que estão indo para uma reunião com o Superintendente ou com outro gestor, e algumas vezes acompanham um grupo de pessoas como representantes.

Os clientes do INCRA, principalmente os presidentes de associação $^{5}$ e lideranças do movimento social ${ }^{6}$, têm profundo conhecimento dos procedimentos burocráticos que guiam a Superintendência Regional em

\footnotetext{
${ }^{5}$ Associações de assentados devem ser criadas nos assentamentos assim que eles são homologados. Registradas em cartório e organizadas de acordo com as determinações do Código Civil, as associações representam o assentamento perante o INCRA e são necessárias para a execução de políticas como crédito, fomento e habitação rural. Os presidentes de cada associação são os portavozes do assentamento na SR, e atuam como mediadores entre o órgão e o assentamento.

6 "Movimento social" é a palavra utilizada pelos servidores da Superintendência para se referir genericamente a todas as organizações representativas dos trabalhadores rurais. As organizações com as quais a SR trabalha são a FETAGRI (Federação dos Trabalhadores da Agricultura), a FETRAF (Federação dos Trabalhadores na Agricultura Familiar), e o MST (Movimento dos Trabalhadores Rurais Sem-Terra). Os servidores utilizam a palavra "movimento social" para se referir às três organizações ou a uma delas de forma não específica.
} 
Marabá. Quase sempre eles sabem o nome técnico de algo de que precisam e sabem os procedimentos burocráticos necessários para consegui-lo. É muito comum ver um cliente perguntando a um servidor questões específicas sobre a burocracia interna do INCRA.

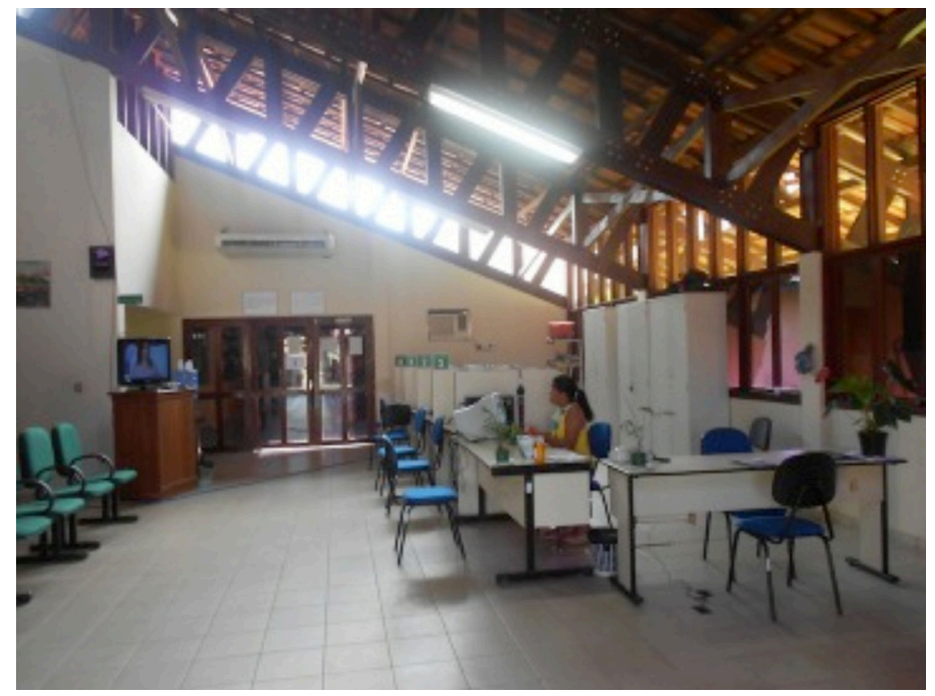

Figura 3: Recepção

Fora do prédio estão algumas famílias acampadas. Elas estão vivendo em barracos feitos de lona preta e madeira montados em uma praça em frente à sede da SR. Pergunto a alguns servidores quem são aquelas pessoas e eles me explicam que elas são o que sobrou de um grande acampamento organizado pelos movimentos em junho de 2011, três meses antes de minha chegada a Marabá. Cerca de 5 mil pessoas estiveram acampadas na sede da Superintendência Regional por aproximadamente 46 dias. A manifestação foi organizada conjuntamente pelos movimentos sociais que atuam na região com o propósito de pressionar pelo andamento da reforma agrária no sul e no sudeste do Pará.

As reivindicações foram apresentadas em uma pauta unificada, que incluía desapropriação das propriedades especificadas, construção e reforma de estradas em alguns assentamentos, mais recursos para créditos aos assentados e universalização do serviço de assistência técnica para todos os assentamentos da região. Quando perguntei ao Superintendente quais foram os resultados dessa mobilização, ele me disse que depois de 46 dias de acampamento e de negociações em nível regional, o presidente do INCRA 
veio a Marabá para negociar pessoalmente com os movimentos. Ele garantiu um aumento extraordinário no orçamento da Superintendência Regional para que ela pudesse atender às demandas apresentadas pelos movimentos. O orçamento programado para a regional de Marabá, no ano de 2011, era de 8 milhões de reais. Depois das negociações entre as lideranças dos movimentos e o presidente do INCRA, o orçamento destinado a Marabá foi para 40 milhões, a serem utilizados para atender às prioridades estabelecidas na pauta dos movimentos sociais. O Ministro de Desenvolvimento Agrário, posteriormente, autorizou o novo orçamento, e os movimentos desocuparam a sede da SR, desfazendo o acampamento que havia durado mais de um mês. As famílias foram desmontando suas barracas e saindo da sede do INCRA em Marabá, exceto algumas que não tiveram suas demandas de desapropriação contempladas e continuaram acampando em uma praça ao lado da SR (27).

Quando cheguei, em outubro de 2011, os servidores estavam trabalhando para cumprir a programação estabelecida pela presidência do INCRA e pela Superintendência nas negociações com os movimentos que seguiram o grande acampamento de junho. Com um aumento no orçamento destinado a atender às demandas específicas dos movimentos sociais, os servidores da SR de Marabá estavam agora trabalhando com um calendário apertado e de acordo com novas prioridades. Uma das mudanças na prioridade das políticas foi determinada pelo aumento significativo do orçamento destinado à assistência técnica. A política de assistência técnica, à qual até então tinha se dado menos importância na SR, se tornou prioritária após a aceitação da pauta apresentada pelos movimentos e após a liberação de uma grande quantidade de recursos para sua execução. Uma equipe especializada do INCRA de Brasília tinha vindo da sede especificamente para auxiliar os servidores de Marabá na execução da política de assistência técnica.

Servidores têm diferentes opiniões sobre a mobilização de junho de 2011 e sobre seus impactos em seu trabalho. Alguns apontam que a ação organizada pelos movimentos foi fundamental para viabilizar o trabalho da Superintendência, porque resultou em um aumento significativo no orçamento, permitindo a execução de ações que não podiam ser realizadas antes por falta de recurso. Outros servidores argumentam que os movimentos sociais são parceiros do INCRA e que, sem suas ações, a autarquia dificilmente sobreviveria. Os servidores responsáveis pela execução da política de assistência técnica apresentaram em um seminário interno a evolução de seu trabalho até aquele momento. O título da apresentação era "Assistência técnica: uma conquista dos movimentos sociais após a jornada de lutas de 2011". 


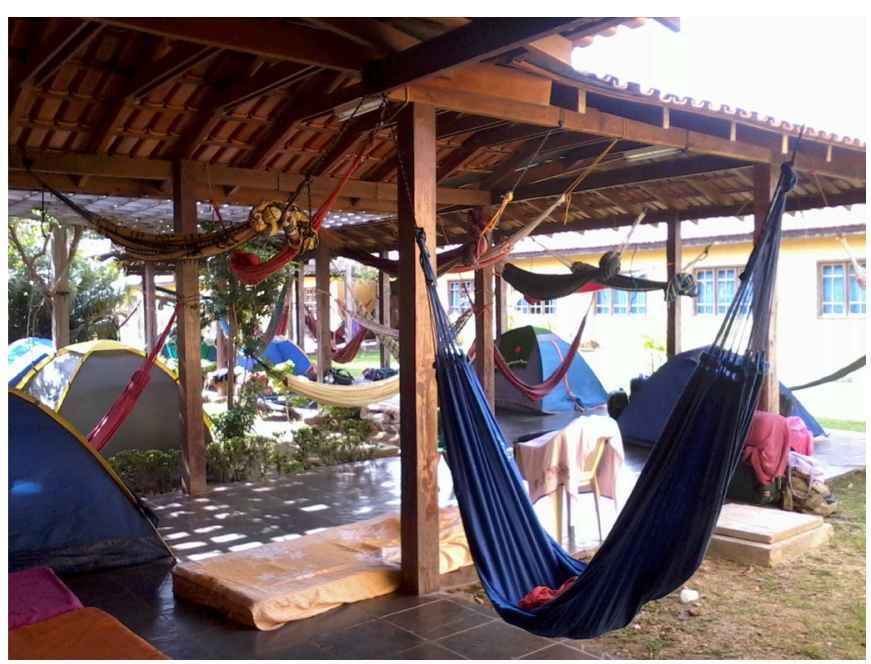

Figura 4: Ocupação do MSR na SR-27 em março de 2012

Juntamente a essas impressões sobre o papel dos movimentos sociais, os servidores também argumentam que, algumas vezes, a relação fica complicada quando as demandas dos movimentos atropelam sua agenda de trabalho. Normalmente, quando os movimentos pressionam com ações coletivas, o Superintendente faz compromissos e estabelece prazos para que as reivindicações sejam atendidas pela SR. Os servidores então têm que se apressar para terminar o trabalho que estão fazendo, ou, em muitas ocasiões, parar o que estão fazendo e se dedicar a outra atividade necessária ao cumprimento dos acordos com o movimento. Alguns servidores também descrevem experiências negativas que ocorreram durante o acampamento de junho de 2011, como roubos, vandalismo, bagunça e depredação do local de trabalho - o que teria ocorrido quando os movimentos "invadiram a Superintendência”.

De volta à recepção, um grupo de pessoas, acompanhada por uma liderança do movimento, acaba de entrar na SR para participar de uma reunião com o Superintendente.Acompanho-os em seu caminho dentro daSuperintendência, e, após meia hora de espera, entramos na sala de reuniões juntamente com o Superintendente, com seu Chefe de Gabinete, e com outros servidores.

A liderança sindical começa se apresentando e dizendo que estava ali acompanhando uma associação de acampados, representada pela FETRAF. Explica que a propriedade que pleiteavam, e na qual estavam acampados, deveria ter sido desapropriada há mais de um ano, de acordo com um compromisso estabelecido com o INCRA. Contudo, o processo havia se 
perdido na burocracia da Superintendência, e o acordo não estava sendo cumprido.

O representante da associação de acampados adiciona que a propriedade já havia sido declarada como improdutiva, principal critério para a desapropriação, mas ainda não havia sido desapropriada. Ele, em nome das famílias acampadas, requeria formalmente que o INCRA concluísse o processo de expropriação o mais rápido possível e criasse o projeto de assentamento para as famílias acampadas. O representante sindical destaca que o movimento pautou formalmente essa propriedade ao INCRA há muitos anos, e que a autarquia já deveria ter finalizado o processo de expropriação.

Pergunto a um dos servidores sentados ao meu lado o que a liderança quer dizer ao afirmar que o movimento já pautou formalmente a propriedade ao INCRA. Ele me explica que a SR só desapropria terras que são pleiteadas pelos movimentos sociais. Posteriormente, em entrevista, o Chefe da Divisão de Obtenção de Terras da SR me esclareceu por que eles trabalham dessa forma: o INCRA não tem recurso suficiente para inspecionar todas as áreas passíveis de desapropriação para reforma agrária e, por isso, trabalha apenas com áreas indicadas pelos movimentos. Geralmente, esse processo se inicia quando o movimento envia à SR um ofício dizendo que determinada associação, representada pelo movimento, solicita que a propriedade na qual estão acampadas as famílias relacionadas (há sempre uma lista em anexo) seja desapropriada para a criação de um assentamento pelo INCRA. Esses ofícios normalmente são enviados depois que as famílias já ocuparam a área e já estabeleceram um acampamento na propriedade ou às suas margens. Em cada ofício há uma lista com os nomes dos representantes das famílias e com o nome da associação de acampados que coordena o acampamento eles ficam anexados à carta oficial encaminhada pelo movimento em papel timbrado.

O servidor Chefe me explica ainda que essa é a forma usual de acordo com a qual o setor da SR responsável pela obtenção de terras para reforma agrária trabalha: "sempre em parceria com os movimentos sociais" ". Essa relação

\footnotetext{
7 A possibilidade de indicação, pelos movimentos, de áreas a serem desapropriadas está fundamentada pelo Decreto 2.250, que decreta: "As entidades estaduais representativas de trabalhadores rurais e agricultores poderão indicar ao órgão fundiário federal ou ao órgão colegiado (...) áreas passíveis de desapropriação para reforma agrária” (Decreto 2.250, Artigo $1,1997)$. Todos os processos administrativos de desapropriação que consultei na SR, ao longo dos nove meses de campo, se iniciavam com um ofício enviado pelos movimentos que solicitava formalmente a desapropriação da área.
} 
de parceria implica o reconhecimento de um acampamento - geralmente representando por um movimento - pela SR como forma de acesso às terras da reforma agrária.

Em resposta às falas da liderança sindical e do representante do acampamento, o Superintendente Regional esclarece que a SR está fazendo tudo o que pode para concluir o processo de desapropriação, mas, atualmente, não há recurso financeiro disponível para pagar a indenização ao proprietário, o que está atrasando o processo. As lideranças respondem que os compromissos estabelecidos entre o INCRA e os movimentos não estavam sendo cumpridos, o que poderia ter consequências drásticas, uma vez que estava cada vez mais difícil controlar a ansiedade da base, que ansiava pela terra. A iminência de um conflito e a existência de tensão social aparecem como justificativas de quase todas as lideranças de movimentos, e também dos servidores, quando estes querem argumentar pela aceleração do processo.

Às colocações das lideranças, o Superintendente responde recordando aos presentes que seus representantes no Congresso - a bancada da reforma agrária e, principalmente, os parlamentares da região sul e sudeste do Pará estavam fazendo o possível na esfera da política institucional para conseguir a liberação de mais recursos para a SR-27. Ele menciona especificamente o trabalho de alguns legisladores da região comprometidos com a causa da reforma agrária e que estavam agindo em Brasília, tentando agendar reuniões com representantes do Executivo para discutir o aumento no orçamento para reforma agrária naquela zona emergencial de conflito, a região sul e sudeste do Pará.

Dentre os legisladores mencionados, está uma deputada estadual que foi Superintendente daSR-27. Ela esteve quatro anos à frente da Superintendência e no ano seguinte se elegeu para o cargo legislativo, no qual se mantém pelo segundo mandato. Juntamente com seu marido, atual Chefe de Gabinete do Superintendente, foi uma das fundadoras do PT na região de Marabá, no início dos anos 1980. A partir da articulação com o movimento sindical rural e com outras correntes, eles fundaram uma tendência local do partido, o "PT pra Valer", que atualmente tem como parte importante de sua base os assentados do INCRA.

Os candidatos dessa tendência sempre falam a favor das políticas de reforma agrária em seu discurso oficial. Nas campanhas eleitorais, as lideranças dos movimentos geralmente apoiam esses candidatos nos acampamentos e assentamentos que representam. Algumas vezes, lideranças que saem de 
assentamentos se candidatam pelo "PT pra Valer" e por outras tendências do PT e de outros partidos e disputam eleições municipais para vereadores e, em alguns casos, para prefeitos.

O "PT pra Valer", tendência local mais forte em Marabá, tem a prerrogativa de indicar gestores para cargos de comissão na SR-27, notadamente o cargo de Superintendente. De acordo com acordos de composição partidária definidos ainda no período de campanha eleitoral para a presidência, os grupos políticos mais fortes aliados ao partido governista em cada região têm o aval do Presidente para indicar Superintendentes para as respectivas regionais do INCRA em sua área de influência política. Esses arranjos políticos são feitos em todas as SR do Brasil. De acordo com os dados disponíveis no Portal da Transparência, consultado em novembro de 2013, 17 dos 30 Superintendentes Regionais exerciam cargos de comissão, de livre nomeação ${ }^{8}$. As nomeações são feitas pelo grupo político de maior influência na área de atuação de cada SR.

No início de 2011, a tendência local "PT pra Valer" indicou para o cargo de Superintendente um ex-militante do MST, filiado ao partido, que veio de Santa Catarina em uma brigada do movimento e que se instalou no Pará há alguns anos, onde foi assentado pelo INCRA e cursou agronomia graças ao PRONERA (Programa de Educação na Reforma Agrária).

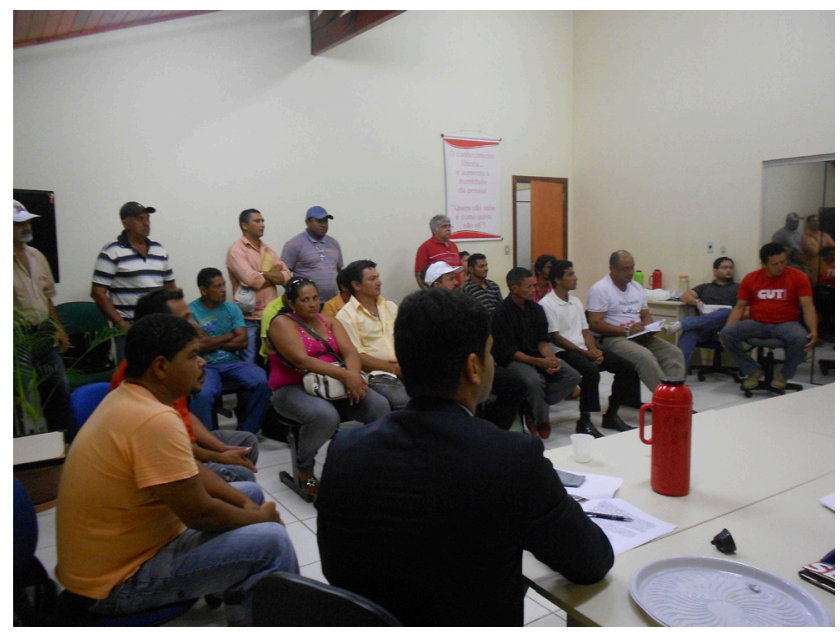

Figura 5: Reunião com lideranças de movimentos na sala de reuniões da SR

\footnotetext{
${ }^{8}$ A consulta ao Portal da Transparência também mostrou que da força de trabalho total do INCRA 127 servidores exercem cargos comissionados, ou seja, não são servidores de carreira.
} 
Esse Superintendente, que tem grande familiaridade com os movimentos da região, está agora tentando costurar um acordo com as famílias acampadas presentes da reunião, o qual possa resolver temporariamente o problema dos acampados enquanto a SR aguarda a liberação de recursos para a indenização do proprietário. Ele sugere que os coordenadores do acampamento comecem a fazer uma triagem com as famílias acampadas para auxiliar o trabalho de seleção e cadastramento de futuros clientes, o que será feito por servidores do INCRA no local. A autarquia tem uma série de regras para o assentamento de famílias através do Programa Nacional de Reforma Agrária. Os clientes a serem assentados devem ter baixa renda, devem estar dispostos a viver e produzir no lote adquirido, não podem ser funcionários públicos e não podem ter outra propriedade rural. Mulheres chefe de família e famílias com muitos dependentes também têm prioridade. Para a seleção e cadastro de beneficiários, o INCRA deve levar em consideração todos esses critérios, especificados em normativa interna9 ${ }^{9}$.

Mas essa é apenas a superfície formal de um processo muito mais complexo de seleção de clientes. Não há nenhuma regra escrita que diga que famílias a serem beneficiadas pelo programa de reforma agrária devem estar associadas a movimentos sociais ou que devem estar acampadas. Na prática, contudo, esses critérios informais são amplamente respeitados pelos servidores da SR27. Cada servidor os conhece bem e age em conformidade com eles. Os movimentos são os interlocutores do INCRA por excelência, processo que se construiu ao longo do tempo a partir da ação dos movimentos de organização dos trabalhadores rurais, que culminou na própria criação da demanda por reforma agrária, cristalizada nas categorias "sem terra", "acampados" e "movimento", a partir das quais as políticas públicas de reforma agrária são formuladas e executadas. Famílias sem-terra, como clientes potenciais da reforma agrária, só têm acesso à autarquia por meio dos movimentos. E a associação de famílias individuais aos movimentos implica a necessidade de que elas participem de um acampamento. Mesmo que não haja nenhuma regra formal que prescreva isso, os clientes do INCRA são inicialmente selecionados pelos movimentos, assim como o são as propriedades a serem desapropriadas. Sobre isso é importante notar que uma das análises que

\footnotetext{
${ }^{9}$ A norma interna que orienta o cadastramento de famílias é a Norma de Execução 45, de 2005, que "Dispõe sobre procedimentos para seleção de candidatos ao Programa Nacional de Reforma Agrária”.
} 
parte dos servidores da SR faz sobre a relação de parceria com os movimentos sociais é a de que, sem a atuação deles, não haveria políticas de reforma agrária. $^{10}$

Nesse sentido, quando o Superintendente pede às lideranças que realizem uma triagem com as famílias acampadas, o que ele está de fato pedindo é que elas distingam, entre as famílias já selecionadas pelo movimento, aquelas que estão em conformidade com os critérios oficiais do INCRA e aquelas que não o estão. Isso significa que o Estado reconhece e endossa os critérios de seleção dos movimentos, aplicando seus critérios formais ao grupo de famílias previamente selecionado pelo movimento e que já está organizado em um acampamento. É importante lembrar que os movimentos conhecem bem os critérios formais de seleção estabelecidos nas normativas internas do INCRA e seguem também esses critérios no momento de selecionar famílias para o acampamento. Todavia, é comum a presença no acampamento de famílias que não têm o perfil exigido pelo INCRA, como as que já foram assentadas ou que têm um trabalho fixo na cidade. Durante o cadastro e seleção oficial feita pelos servidores do INCRA, essas famílias geralmente são excluídas pelo sistema oficial e não ingressam como clientes da reforma agrária.

É por isso que o Superintendente diz às lideranças que o processo de triagem feito pelos movimentos irá ajudar o trabalho do INCRA ao eliminar famílias que não poderiam se tornar clientes de acordo com as regras da autarquia. Após essa triagem inicial, ele garante que irá enviar uma equipe de servidores ao acampamento para o cadastramento de futuros clientes. Essa solução, de acordo com ele, irá economizar tempo e agilizar o trabalho da equipe do INCRA, uma vez que os servidores só irão cadastrar as famílias passíveis de serem assentadas. Ele conclui argumentando que "com a parceria dos movimentos o processo correrá mais rápido”.

As lideranças presentes concordam com a solução dada pelo Superintendente, ressaltando que a relação de parceria com o INCRA tem sido muito importante para o andamento das políticas de reforma agrária na região. A liderança sindical conclui elogiando a proposta do Superintendente que "respeita a organização interna do movimento". Com isso, ele quer

\footnotetext{
${ }^{10}$ Wolford (2010) assinala que a participação do MST na implementação de políticas junto ao INCRA se deve à histórica falta de prioridade do governo brasileiro em relação ao tema da reforma agrária, o que culminou em um órgão mal financiado e sem pernas para executar todas as suas atividades, e na delegação de algumas tarefas para o movimento.
} 
dizer que a SR respeita e não interfere no processo de seleção de famílias feito pelo movimento. Para concluir a reunião, o Chefe de Gabinete do Superintendente assinala que o processo de seleção feito pelo movimento é muito importante para a SR, uma vez que os movimentos estão mais perto dos trabalhadores rurais e potenciais clientes do INCRA e conhecem melhor as famílias que têm perfil de clientes da reforma agrária.

A reunião termina, e a liderança sindical começa uma conversa informal com os servidores sobre as eleições municipais de outubro de 2012. Ele é uma liderança sindical antiga e bem conhecida na região, que está presente quase que diariamente na SR-27. Geralmente, acompanha grupos de trabalhadores e associações de acampados e de assentados apoiados pela FETRAF nos trâmites internos da Superintendências, como nessa reunião com o Superintendente. Todos os servidores da SR o conhecem e agora, ao final da reunião, ele comenta com os servidores presentes na sala sobre sua candidatura a vereador pelo município de Marabá nas próximas eleições. Ele conta que decidiu se candidatar após articulação com o "PT pra Valer", que está apoiando sua candidatura.

\section{Considerações finais}

Este artigo teve como objetivo mostrar como as ações dos movimentos sociais podem ter impacto nas políticas públicas. O argumento central é o de que, para avaliar como movimentos influenciam políticas, é necessário olhar para o Estado, onde as políticas são feitas. Analisei o caso da influência dos movimentos sociais rurais na autarquia responsável pela implementação das políticas de reforma agrária a partir da observação etnográfica de uma Superintendência Regional no INCRA. Por meio da observação, foi possível identificar que os movimentos rurais têm uma grande influência na definição de como as políticas de reforma agrária são implementadas pela SR. Essa influência é exercida de diferentes formas.

Os movimentos estão completamente familiarizados com os procedimentos burocráticos da autarquia e se relacionam de forma próxima e rotineira com os servidores. Olhando a partir de dentro da Superintendência, foi possível apreender o grande poder de barganha que os movimentos têm quando realizam ações coletivas massivas, como o grande acampamentos em junho de 2011 na sede da SR(27). A importância dos movimentos para a autarquia responsável pela execução da reforma agrária fica evidente quando se olha 
para o significativo aumento no orçamento destinado à SR autorizado após a ocupação de junho. A observação etnográfica também me permitiu ver a complexidade e heterogeneidade das posições dos servidores quanto ao papel dos movimentos. Suas ações claramente têm impacto no trabalho cotidiano dos servidores da SR, e, ao mesmo tempo em que os burocratas reconhecem a importância dos movimentos, eles também se sentem pressionados e, algumas vezes, sobrecarregados pela quantidade e pela urgência das demandas.

A influência dos movimentos sociais nas políticas públicas também é revelada pela descrição da relação de "parceria". Essa noção, utilizada tanto pelas lideranças como pelos servidores para qualificar a relação entre INCRA e movimentos, expressa os elementos por meio dos quais os movimentos influenciam a implementação das políticas. O movimento é parceiro do INCRA em dois processos importantes: a definição de propriedades a serem expropriadas para propósitos de reforma agrária e a seleção de famílias que serão clientes do INCRA. A primeira forma de cooperação está diretamente conectada ao repertório do movimento de ocupação e acampamento. O repertório é a linguagem pela qual se comunica efetivamente ao INCRA quais áreas devem ser desapropriadas.

O segundo processo no qual a relação de parceria se expressa é a seleção de famílias. Nesse aspecto, as ações coletivas dos movimentos sociais, especificamente o acampamento como forma de reivindicar reforma agrária, foram completamente internalizadas nas práticas da SR. Não apenas os servidores respeitam a seleção de famílias organizadas pelos movimentos, mas também consideram o acampamento como o meio legítimo de acesso às políticas de reforma agrária. É importante ressaltar que esse "aprendizado" dos repertórios dos movimentos como forma reconhecida e rotineira de executar as políticas não é comum apenas dentre os servidores ligados ao partido e aos movimentos e que ocupam cargos de comissão. Essa forma de trabalhar orientada pelas ações coletivas utilizadas pelos movimentos é aprendida e atualizada constantemente por servidores públicos aprovados em concursos recentes.

Para apreender a complexidade da relação de parceria entre movimentos e INCRA, é relevante ressaltar também o papel do partido político. O PT permeia a relação entre os atores e tem influência tanto sobre as ações da Superintendência como sobre as ações dos movimentos. O partido é a cola que liga movimentos sociais a alguns servidores públicos, tais como o Superintendente, o Chefe de Gabinete e outros gestores que ocupam cargos de confiança. É devido a seus laços com o PT e com os movimentos que 
esses gestores podem construir acordos e articular soluções entre a SR e as lideranças. Também é importante lembrar que servidores e lideranças algumas vezes se tornam políticos, e que lideranças e militantes partidários algumas vezes se tornam servidores.

O modelo proposto por Jenkins e Klandermans (1995) oferece uma boa orientação para a interpretação do caso analisado aqui, na medida em que considera a influência mútua que movimentos sociais (que representam cidadãos) podem ter sobre o Estado e sobre o sistema político representativo. O PT, como parte desse sistema, apareceria no modelo do losango como um conector entre cidadãos, movimentos e Estado. O Estado, representado no estudo pelo braço do Executivo responsável por implementar políticas de reforma agrária, também está conectado ao partido e aos movimentos sociais, exercendo influência e sendo influenciado por ambos.

Em um nível mais abrangente, esse modelo ajuda a compreender a interação entre INCRA, movimentos, partidos e clientes, ao propor a noção de que esses atores estão conectados e exercem influência uns sobre os outros. A observação etnográfica apontou, contudo, para uma sobreposição entre atores localizados nos diferentes vértices do losango proposto por Jenkins e Klandermans (1995): o representante estatal (Superintendente) ex-militante do PT; as lideranças do movimento social que passam a ocupar cargos no sistema político representativo por meio do partido; os servidores do Executivo (de carreira ou não) que pleiteiam cargos eletivos.

Essas sobreposições apontam para o fato de que não se trata apenas da influência de um tipo de ator (ou vértice do losango) sobre o outro, uma vez que as fronteiras que os delimitam não estão inteiramente fechadas. No caso da "relação de parceria" observada, fica claro que os movimentos têm grande influência na SR e nas políticas de reforma agrária devido, em grande medida, à sua capacidade de organização, mobilização e pressão. Mas também fica claro que essa influência se deve ao "trânsito institucional" de militantes pelo Estado (SILVA; OLIVEIRA, 2011), e à atualização, nas práticas cotidianas dos servidores, da legitimidade do movimento como representante dos clientes. 


\section{Referências}

AUYERO, Javier.

(2002). La Protesta: retratos de la beligerância popular em la Argentina democrática. Centro Cultural Rojas-UBA. Buenos Aires.

ASSIS, Wagner.

(2007). A construção da representação dos trabalhadores rurais no sudeste paraense. Tese de Tese de doutorado apresentada a Universidade Federal Rural do Rio de Janeiro.

BURSTEIN, Paul.

(1999). Social movements and public policy. In: Marco Giugni; Doug McAdam; Charles Tilly (Eds.); How social movements matter. Mineapolis: University of Minesotta Press.

\section{BRASIL.}

(1997). Decreto ${ }^{\circ} 2.250$, de 11 dejunho. Dispõe sobre a vistoria em imóvel rural destinado à reforma agrária e dá outras providências

DELLA PORTA, Donatella.; DIANI, Mario. (2006). Social movements: an introduction. Massachusetts: Blackwell Publishing.

DUB0IS, Vincent.

(2010). The bureaucrat and the poor: encounters in French welfare offices. Burlington: Ashgate.

FERNANDES, Bernardo Mançano.

(2003). 0 MST e os desafios para a realização da reforma agrária no governo Lula. Observatorio Social de América Latina, vol. 11, p. 31-40.

GOLDSTONE, Jack.

(2003).Introduction: Bridging institutionalized and nonistitutionalized politics. In: Jack Goldstone; States, Parties and Social Movement, p. 281-309.

HERZFELD, Michael.

(2005). Political Optics and the Occlusion of Intimate Knowledge. American Anthropologist, vol. 107, Issue 3, pp. 369-376, 2005.
INSTITUTO NACIONAL DE COLONIZAÇÃO E REFORMA AGRÁRIA (INCRA). (2005). NORMA DE EXECUÇAO/INCRA/DT/ $n^{\circ} 45$, de 25 de agosto. Dispõe sobre procedimentos para seleção de candidatos ao Programa Nacional de Reforma Agrária.

INTINI, João Marcelo.

(2004). Luzes e Sombras. Negociação e diálogo no sul e sudeste do Estado do Pará. Dissertação de Mestrado apresentada a Universidade Federal do Pará.

JENKINS, John. Craig; KLANDERMANS, Bert.

(1995). The Politics of Social Protest: comparative perspectives on states and social movements. University of Minesota.

JONHSTON, Hank.

(2011). States and social movements. Malden, MA: Polity Press.

LIPSKY, Michael.

(1980). Street-level Bureaucracy. Dilemmas of the indiviadual in the public service. Nova Iorque: Russel Sage Foundation.

MEDEIROS, Leonilde.

(2000). Conflictos sociales rurales en el Brasil contemporâneo. Observatorio Social de America Latina, vol. 1, n. 2, p. 37-44.

MEYER, David.

(2003). How social movements matter. Contexts, vol. 2, Issue, 4, p.30-35

MUNK, Gerardo.

(1995). Actor Formation, Social Co-Ordination, and Political Strategy: Some Conceptual Problems in the Study of Social Movements. Sociology, vol. 29, n. 4.

NAVARRO, Zander.

(2010). The Brazilian landless movement: critical times. REDES, vol. 15, n. 1, p. 196223. 
ONDETTI, Gabriel.

(2008). Land, protest and politics: the landless movementand the struggleforagrarian reform in Brazil. State College, PA: Pennsylvania State University Press.

ONDETTI, Gabriel.

(2006). Repression, opportunity, and protest: Explaining the takeoff of Brazil's Landless Movement. Latin American Politics and Society, vol. 48, Issue 2, p. 61-94.

PALMEIRA, Moacir.

(1994). Burocracia, política e reforma agraria. In: Leonilde Medeiros et al. (Orgs.); Assentamentos Rurais: uma visão multidisciplinar. São Paulo: Editora Unesp.

ROSA, Marcelo.

(2004). As novas faces do sindicalismo rural brasileiro: a reforma agrária e as tradições sindicais na Zona da Mata de Pernambuco. Dados, vol. 47, n. 3.

ROSA, Marcelo.

(2011). O Engenho dos Movimentos: reforma agrária e significação social na zona canavieira de Pernambuco. Rio de Janeiro: Garamond.

SCOT, James.

(1998). Seeing like a state: how certain schemes to improve the human condition have failed. Yale: University Press.

SHARMA, Aradhana; GUPTA, Akhil.

(2006) .The Anthropology of the State: a reader. 0xford: Blackwell.

SIGAUD, Lygia.

(2005). As condições de possibilidade das ocupações de terra. Revista Tempo Social, vol. 17, n. 1, p. 255-280.

SILVA, Marcelo; OLIVEIRA, Gerson.

(2011). A face oculta dos movimentos sociais: trânsito institucional e intersecção EstadoMovimento - uma análise do movimento de economia solidária no Rio Grande do Sul. Sociologias, ano $13, n^{\circ} 28$.
TARROW, Sidney.

(1998). Power in Movement: Social movements. Collective Action and Politics. Cambridge: Cambridge University Press.

TILLY, Charles.

(2006). Regimes and Repertoires. Chicago: Chicago Press.

(1995). Popular Contention in Great Britain, 1758-1834. Cambridge, MA: Harvard University Press.

VERGARA-CAMUS, Leandro.

(2009). The Politics of the MST: Autonomous Rural Communities, the State, and Electoral Politics. Latin American Perspective, vol. 36, Issue 178.

WOLFORD, Wendy.

(2010). Participatory democracy by default: land reform, social movements and the state in Brazil. The Journal of Peasant Studies, vol. 37, n. 1, p. 91-109.

WOLFORD, Wendy; WRIGHT, Angus.

(2003). To Inherit the Earth. California: Food First Book.

ZALD, Mark.

(1996). Culture, Ideology, andstrategicframing. In: Doug McAdam; John McCarthy (Orgs.); Comparative perspective on social movements: Political opportunities, mobilizing structures, and cultural framings. Cambridge: Cambridge University Press.

\section{Recebido em}

dezembro de 2013

\section{Aprovado em}

fevereiro de 2015 